\title{
Investigations on the occurrence of different wetting regimes in laser brazing of zinc-coated steel sheets
}

\author{
Thorsten Mattulat $^{1}$ (1) $\cdot$ Helge Kügler ${ }^{1} \cdot$ Frank Vollertsen $^{1,2}$
}

Received: 16 September 2019 / Accepted: 20 December 2019/Published online: 25 January 2020

(C) The Author(s) 2020

\begin{abstract}
In the automotive industry, the seam edge quality of laser brazed seams is a crucial factor for the required high optical quality standards of customer-visible connections of zinc-coated car body parts. The type of zinc coating is decisive for the resulting geometry of the seam edges, which are aspired to be straight. Especially brazing of hot-dip galvanised steel with conventional brazing setup is not resulting in seam edges which fulfil the required optical quality. In this study, the wetting of copper-based filler wire on electrogalvanised and hot-dip galvanised steel sheets is analysed to increase the understanding of the influence of the wetting fronts on the seam edge quality. For this, the wetting fronts are determined in high-speed camera images and the resulting seam edges are captured by microscopic pictures. The results show that two major wetting regimes occur on both types of zinc coatings but with a different occurrence probability: one with a steep wetting front and zinc evaporation in front of wetting ("steep-angle-wetting") and one where liquid zinc connects with the wetting front and creates a flat wetting angle ("flat-anglewetting"). It is found that the resulting seam edge quality is mainly depending on the present wetting regime. However, for flatangle-wetting, in the regime with insufficient seam edge quality, a self-stabilising effect is identified, which is responsible for a missing process window for brazing of hot-dip galvanised steel with sufficient seam edge quality.
\end{abstract}

Keywords Laser brazing $\cdot$ Zinc-coated steel $\cdot$ Wetting $\cdot$ Optical seam quality

\section{Introduction}

Laser beam brazing is used in automotive serial production since 1997 [1]. In addition to achieving the strength requirements for car body parts, the process is distinguished by the high optical seam qualities that can be attained [2]. Therefore, it is used in car body construction to connect parts with customer-visible seams [3]. Standard application provides, for example, the connection between the two-part trunk lid [4] or the connection of roof and side panel [5]. These body

Recommended for publication by Commission XVII - Brazing, Soldering and Diffusion Bonding

Thorsten Mattulat mattulat@bias.de

1 BIAS - Bremer Institut für angewandte Strahltechnik $\mathrm{GmbH}$, Klagenfurter Str. 5, 28359 Bremen, Germany

2 Faculty of Production Engineering, University of Bremen, Klagenfurter Str. 5, 28359 Bremen, Germany parts in automotive construction are by default zinc-coated for corrosion protection [6].

The type of zinc coating in laser brazing has a major influence on factors like the wettability [7] or the resulting seam quality [8]. Therefore, in automotive production, electrolytical galvanised steel is conventionally used in laser brazing to achieve high optical seam qualities. However, because of higher corrosion resistance and lower cost of material, there is the effort to use hot-dip galvanised steel sheets for the car body parts [9]. This type of zinc coating causes problems for laser brazing such as increased spatter formation and uneven seam edges [10]. As a reason for the decreased seam edge quality, Reimann discusses a lower absorption of laser radiation by the hot-dip galvanised coating than in electrolytical galvanised steel [11]. In electrolytical galvanised steel, the zinc, which has a comparatively low evaporation temperature of $907{ }^{\circ} \mathrm{C}[12]$, evaporates prior to the wetting process, while in hot-dip galvanised steel, the zinc is just melted and merges with the copper melt [11]. The zinc locally increases the wetting length [13], depending on the zinc amount in the seam edge, and by that, uneven seam edges 
were created. The presence of zinc in the solidified seam edges could be verified by composition analyses in cross sections of the seam by Gatzen et al. for aluminium alloy filler wire in wavelength-dispersive $\mathrm{x}$-ray spectroscopy (WDX) measurements [14] and by Reimann et al. for copper alloy filler wire in energy-dispersive $\mathrm{x}$-ray spectroscopy (EDX) measurements [15]. As reasons for the changing zinc concentrations in the seam edge, Reimann discusses a changing zinc layer thickness, a dynamic movement of the wetting front of the process, inconstant wire feed, structural changes in the zinc layer and local absorption differences [11]. In the industrial serial production, the insufficient seam edge quality is encountered by using tailored beam profiles to evaporate the zinc before melting the filler wire [16]. An approach, which is effective for increasing the seam quality, is to divide the laser spot into three individual spots [9]. Two smaller and leading spots should vaporise the zinc layer next to the filler wire before the filler wire is molten by a centred spot. This leads to a straighter seam edge and a reduction of spatter formation because of a local separation of the zinc evaporation from the molten pool [15]. However, besides to the knowledge that liquid zinc decreases the seam edge quality due to changing wetting lengths, the different wetting mechanisms when connecting liquid zinc with the wetting fronts of the copper melt have barely been investigated.

Further analyses of the wetting behaviour were carried out by Grimm and Schmidt. High-speed camera recording of the process from the top view was done [17]. It is shown that for hot-dip galvanised steel, a cyclic wetting process takes place. The found wetting frequencies of this process increase with increasing process speed; at a speed of $2 \mathrm{~m} / \mathrm{min}$, a frequency of approx. $30 \mathrm{~Hz}$ was detected. Heuberger et al. analysed the processes taking place within one wetting cycle and found that the propagation speed is not steady during the wetting cycle but constantly changing and that in the area between the filler wire and the wetting front constrictions are taking place, which are moving parallel to the process direction [18]. They also found out that the occurrence of notches in the seam edges is synchronous with a peak in the propagation velocity of the found constrictions. It is concluded that the abrupt propagation is triggered by reaching a sufficient temperature for wetting, but due to the fast propagation, wetting errors occur on not properly preheated positions and create notches.

Besides the presented findings, the knowledge about how the wetting process on different zinc-coated surfaces influences the seam edge geometry is still very limited. Therefore, in this paper, the wetting process itself and the influence of the wetting process on the seam edge quality are analysed for differently coated steel sheets and different laser powers. This study aims to increase the understanding of effects that are responsible for insufficient seam edge quality in laser beam brazing.

\section{Experimental}

\subsection{Material}

Steel sheets with dimensions $150 \mathrm{~mm} \times 50 \mathrm{~mm} \times 0.75 \mathrm{~mm}$ were used. With the grades DX54+Z100 (hot-dip galvanised) and DC06+ZE75/75 (electrolytically galvanised), two materials with different types of zinc layers were investigated. CuSi3Mn1 material with a diameter of $1.2 \mathrm{~mm}$ was used as filler wire. The material has a melting range from 965 to $1035^{\circ} \mathrm{C}$. The chemical composition is given in Table 1 .

The used filler wire and base materials are common for industrial application of laser brazing in car body construction.

\subsection{Absorption coefficient of zinc layer}

For measuring the absorption coefficient of the different zinc coatings, an integrating sphere was used. The measuring was carried out like described by Kügler and Vollertsen in [19]. The measurement was carried out using the wavelengths $1030 \mathrm{~nm}$ and $1080 \mathrm{~nm}$. In order to identify differences in the absorption coefficients on different sheet sides, both the top and the bottom sides of the sheets are measured.

\subsection{Brazing setup}

In this study, an experimental setup for laser beam brazing of bead-on-plate seams was used. This contains a Trumpf HL4006D solid-state laser with a wavelength of $1064 \mathrm{~nm}$ and a Trumpf BEO D70 focussing optic. The optic was equipped with a fibre of $0.6 \mathrm{~mm}$ core diameter, a collimation length of $56 \mathrm{~mm}$ and a focal length of $280 \mathrm{~mm}$, resulting in a nominal focus diameter of $3.0 \mathrm{~mm}$. All experiments were carried out with laser focus on the sheet surface. The used wire feed system was a Dinse DIX WD 300 in a push-pull configuration. The wire angle was set to $45^{\circ}$, and the wire stick-out to $7 \mathrm{~mm}$. The wire tip was positioned $0.8 \mathrm{~mm}$ inside the laser spot as illustrated in Fig. 1. The brazed seams with a length of $130 \mathrm{~mm}$ were carried out with constant process speed and wire feed rate, $3 \mathrm{~m} / \mathrm{min}$ each. To realise the process movement between laser and specimen, the specimen was moved while the position of the laser beam was kept constant. This allows to use a fixed high-speed camera position to record the process.

In the experiments, the laser power was varied from 2.00 to $3.00 \mathrm{~kW}$ in $0.25 \mathrm{~kW}$ increments for both mentioned types of

Table 1 Chemical composition of the used filler material in wt $\%$

\begin{tabular}{llllllll}
\hline $\mathrm{Si}$ & $\mathrm{Mn}$ & $\mathrm{Fe}$ & $\mathrm{Zn}$ & $\mathrm{Sn}$ & $\mathrm{Pb}$ & $\mathrm{Al}$ & $\mathrm{Cu}$ \\
\hline 2.88 & 0.84 & 0.009 & 0.005 & 0.002 & 0.001 & 0.001 & bal. \\
\hline
\end{tabular}


Fig. 1 Exemplary measurement of the wetting angle on recording of the wetting process
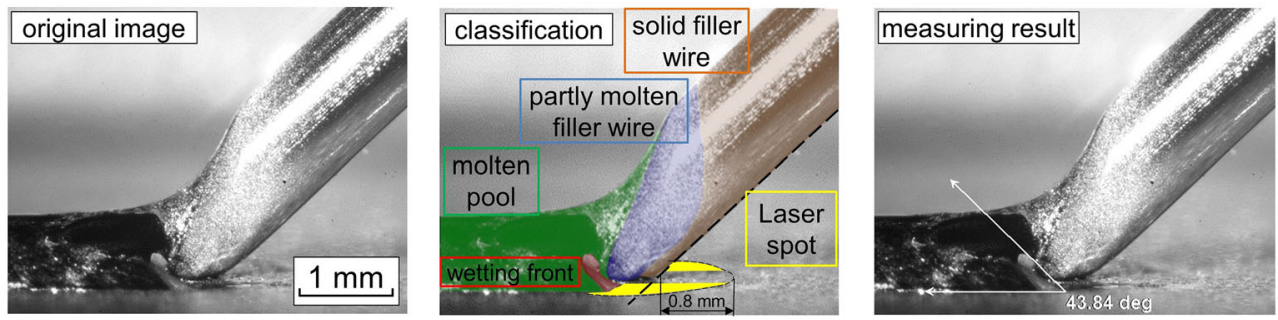

zinc coatings. For statistical coverage, every brazing experiment was carried out three times. Cross sections from the brazed seams with $3.00 \mathrm{~kW}$ were etched (1-vol.\% nital) and analysed considering the maximum melting depth to differ between a brazing and a welding process. Three cross sections for each type of zinc coating were recorded by the microscope Keyence VHX-1000 and measured.

\subsection{Process monitoring}

The high-speed camera Phantom VEO 410L in combination with an extension bellows to increase the magnification of the process zone was used to record the wetting front of the brazing process. Therefore, the camera was positioned orthogonal to the process direction, recording the area, where the filler wire impinges the base material. The camera was positioned with a vertical inclination of $5^{\circ}$ to the sheet surface. With this setup, a stationary recording of the brazing process without considering initial effects at the process start is achieved. The recording started after the process has passed a distance of $55 \mathrm{~mm}$. The synchronised illumination system Cavitar Cavilux HF was used to eliminate process radiation in the camera recording. It illuminates the process with a laser diode of $810 \mathrm{~nm}$ central wavelength. The camera, equipped with an $810 \mathrm{~nm}$ bandpass filter (12 $\mathrm{nm}$ FWHM), only records the backscattered light from the illumination system, and disturbing influences like process radiation are eliminated. The recording parameters are shown in Table 2 .

\subsection{Analysis of the wetting front}

The angle of the wetting front was measured post-process in the lateral high-speed camera recordings, which are shown exemplary in Fig. 1. For this purpose, the vertex of the measured angle is set to the rightmost position of the wetting front at the same y position as the seam edge in the recording. The seam edge is evaluated as the first ray of the angle. The largest angle that can be formed between the horizontal seam edge and the wetting front (red plane in Fig. 1) is considered. This evaluation method is illustrated in Fig. 1. For statistical coverage, the measuring is repeated five times with an evaluation of 1000 frames $(66.6 \mathrm{~ms})$ between each measuring point.

Brazing experiments with immediate process stops were carried out in order to solidify the wetting fronts at the current positions to further analyse the geometry of the wetting front. For that, the laser, the process movement and the wire feed were interrupted at the same time. The solidified wetting fronts were recorded with the optical microscope Keyence VHX-1000.

The seam edges at the position of the high-speed camera recording are captured to analyse the influence of the wetting fronts on the seam edge geometry. Furthermore, cross sections of the seams were made and recorded. For that, the same microscope was used.

\section{Results}

The results of the absorption measurement of differently coated sheets show a significant difference between hot-dip and electrolytical galvanised steel, cf. Fig. 2. It can be seen that the absorption coefficient of hot-dip galvanised steel was approximately $1 / 5$ lower than for electrolytically galvanised steel for both measured wavelengths. The largest difference measured in the absorption coefficient between the top and bottom of the sheet was $3 \%$.

The resulting wetting front geometry and the corresponding seam edge geometry for brazing differently galvanised steel sheets are shown exemplary in Fig. 3. The calculated difference of the absorption of $2.25 \mathrm{~kW}$ incident laser power on electrolytically galvanised sheets (average absorption of $78.8 \%$ ) and of $3 \mathrm{~kW}$ in case of hot-dip galvanised sheets (average absorption of $61.5 \%$ ) is with $72.0 \mathrm{~W}$ very similar. Therefore, in the presented comparison, the effectively absorbed laser radiation from the base material also is very

Table 2 Parameters for process recording

\begin{tabular}{llllll}
\hline $\begin{array}{l}\text { Sample } \\
\text { rate }(\mathrm{Hz})\end{array}$ & $\begin{array}{l}\text { Exposure } \\
\text { time }(\mu \mathrm{s})\end{array}$ & $\begin{array}{l}\text { Resolution } \\
(\mathrm{px} \times \mathrm{px})\end{array}$ & $\begin{array}{l}\text { Total recording } \\
\text { time }(\mathrm{s})\end{array}$ & $\begin{array}{l}\text { Illumination } \\
\text { wavelength }(\mathrm{nm})\end{array}$ & $\begin{array}{l}\text { Illumination pulse } \\
\text { duration }(\mu \mathrm{s})\end{array}$ \\
\hline 15,000 & $10 \mu \mathrm{s}$ & $576 \times 544$ & 1 & 810 & 1.33 \\
\hline
\end{tabular}


Fig. 2 Measured absorption coefficients of different types of zinc coating

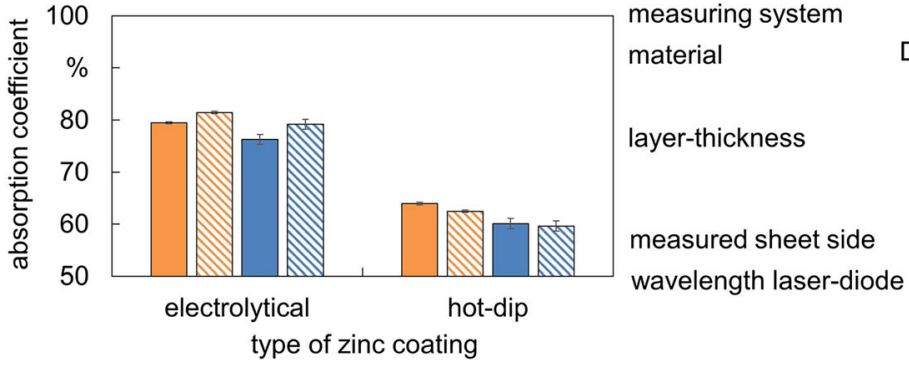

integrating sphere

DC06 + ZE75/75 (electrolytical)

DX54 + Z100 (hot-dip)

electrolytical: nominal $7.5 \mu \mathrm{m}$ hot-dip: nominal $7 \mu \mathrm{m}$

\begin{tabular}{c|cc} 
& Top & Bottom \\
\hline $1030 \mathrm{~nm}$ & $\square$ & $\mathbb{N}$ \\
$1080 \mathrm{~nm}$ & $\square$ & $\mathbb{N}$
\end{tabular}

similar. For electrolytically galvanised steel and a laser power of $2.25 \mathrm{~kW}$, a wetting front with a wetting angle of $46.66^{\circ} \pm$ $3.53^{\circ}$ resulted, which starts near the impinging point of the filler wire. In contrast, the wetting at hot-dip galvanised steel with a laser power of $3 \mathrm{~kW}$ starts on a leading position referred to the impinging point of the filler wire and results in a flatter angle of the wetting front of $29.43^{\circ} \pm 3.01^{\circ}$. The top view of seams on electrolytically galvanised steel sheets shows a straighter seam edge compared with the seams on hot-dip galvanised steel sheets. Furthermore, in electrolytically galvanised steel sheets, the optical appearance in an area besides the seam edges, bordered by a straight edge, is different to the zinc-coated base material in initial condition. In hot-dip galvanised steel, this area cannot be identified and the seam edges are directly connected to the zinc coating. The found differences will be considered as features of two different wetting regimes, named "steep-angle-wetting" and "flat-angle-wetting", characterised by the position and the angle of the wetting front and by the presence of an area, which is connected to the seam edges.

In Fig. 4, it is presented that both wetting regimes can appear in the same brazing process and without changing process parameters. After the occurrence of a process disturbance, the regime in the shown image changed from steep-anglewetting to flat-angle-wetting. At the position in the seam edge, where the regime changes, a wider seam and a defect in the seam edge quality results. After changing the regime to flatangle-wetting, the seam edge straightness decreases.
The images recorded by microscope were evaluated to investigate the frequency of occurrence as a function of laser power and type of zinc coating. Because of the symmetrical bead-on-plate process, only the side of the seam, which was recorded by the high-speed camera, was considered. The regime of flat-angle-wetting was identified by the absence of the previously described areas at the seam edges. The percentages of the length shares of flat-angle-wetting regime in relation to the total measured distance for varied laser powers and zinc coatings are shown in Fig. 5. Furthermore, the density of regime changes, calculated by the number of counted regime changes per measured distance, is presented. It can be seen, that at electrolytical galvanised steel and $2.25 \mathrm{~kW}$, the lowest laser power before incomplete seams occurred, no flat-anglewetting could be detected, so only steep-angle-wetting is present. With increasing laser power, the share of flat-angle-wetting and the density of regime changes increase, and at the highest investigated laser power of $3 \mathrm{~kW}$, the share is $62.63 \% \pm 13.21 \%$ with a density of $0.426 \mathrm{~mm}^{-1} \pm 0.076 \mathrm{~mm}^{-1}$. In contrary, at brazing hot-dip galvanised steel with $2.5 \mathrm{~kW}$, the lowest investigated laser power before incomplete seams occurred, the share of flat-angle-wetting is already $95.68 \% \pm 7.48 \%$ with a density of regime changes of $0.007 \mathrm{~mm}^{-1} \pm 0.012 \mathrm{~mm}^{-1}$. Only flatangle-wetting occurs for increasing laser power to $3 \mathrm{~kW}$.

In Fig. 6, a brazed seam after immediate process stop is shown. With this method, it can be illustrated that both wetting regimes can be present simultaneously on the two sides of the wire. To analyse the visible differences concerning the zinc
Fig. 3 Exemplary wetting front and resulting seam geometry for laser brazing of electrolytical and hot-dip galvanised steel
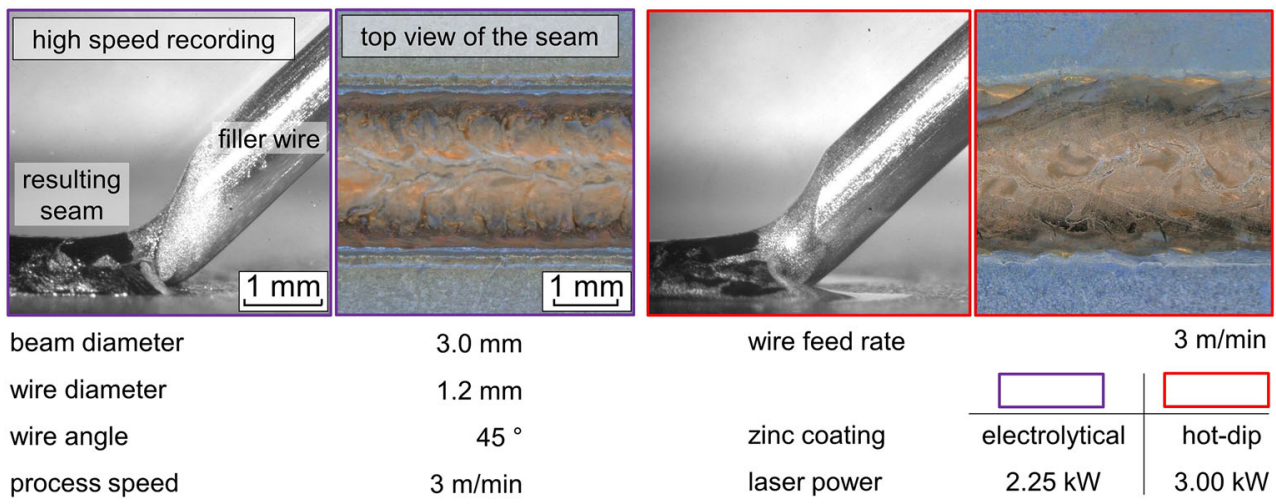
Fig. 4 Different wetting regimes occurring during constant brazing process
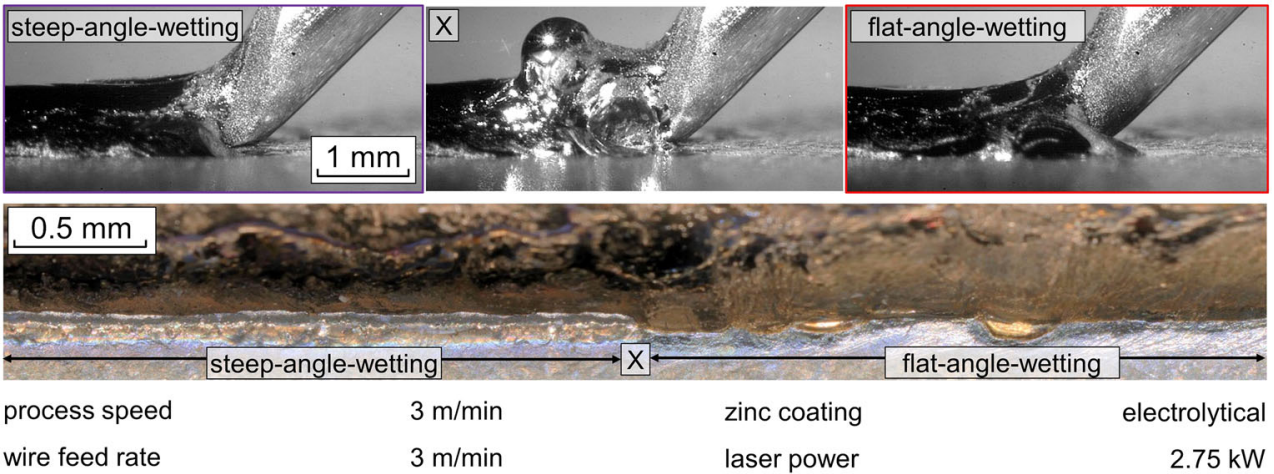

layer, the microscopic images are supplemented with longitudinal grindings for each regime. Here it can be seen that in the case of steep-angle-wetting, the zinc layer is evaporated in the area in front of the wetting front. In the case of flat-anglewetting, this evaporated area cannot be detected and the copper is directly in contact with the zinc layer.

Cross sections of positions with different wetting regimes within the same seam for differently galvanised steel sheets are shown in Fig. 7. These positions again were identified by the presence/absence of the previously described areas at the seam edges. In the case of steep-angle-wetting for both types of zinc coatings, the brazed seam also shows a steeper wetting angle transverse to the process direction than in the case of flat-angle-wetting. Furthermore, in flat-angle-wetting, there is a section at the seam edges, which is directly connected to the zinc layer as well as to the copper alloy of the seam. This section could not be detected in the case of steep-angle-wetting. In addition, it was examined in the cross sections whether melting of the steel sheet occurred. It was found that the melting was negligible. The maximum melting depths of local meltings of the base material beneath the brazed seam with the highest investigated laser beam power of $3.00 \mathrm{~kW}$ are $36.9 \mu \mathrm{m} \pm 14.1 \mu \mathrm{m}$ for electrolytical galvanised and $31.8 \mu \mathrm{m} \pm 5.6 \mu \mathrm{m}$ for hot-dip galvanised steels.

\section{Discussion}

Reimann found in brazing experiments that in the case of brazing electrolytically galvanised steel, a zinc evaporation takes place in front of wetting and shows in EDX measurements that this zinc evaporation is accompanied by an area at the seam edges in which zinc is absent [11]. This area is also identified in longitudinal grindings for the regime of steepangle-wetting (cf. Fig. 6). In the case of hot-dip galvanised steel, a contact of copper melt with liquid zinc avoids the zinc evaporation, which leads to a direct contact of the brazed seam with the zinc coating. It is therefore concluded for this work, that zinc evaporation takes place during steepangle-wetting, which does not occur during flat-angle-wetting. In this study, it can be shown that both regimes can occur with both coatings but the kind of zinc coating determines the probability of occurrence of a particular regime (cf. Fig. 5). As described by Koltsov et al., the dissolution of zinc in the wetting front results in a reduction of the melting temperature of the copper alloy and therefore increases the wetting [13]. In the brazing process, this leads to a flatter angle of the wetting front in process direction, and by that, a leading wetting front relative to the impinging point of the filler wire, cf. Fig. 3. The merging of liquid zinc and copper
Fig. 5 Length share of flat-anglewetting and density of regime changes, determined by analysing the seam edges

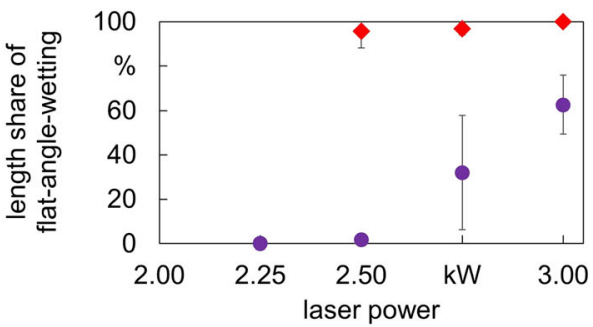

wire diameter process speed

$1.2 \mathrm{~mm}$ wire feed rate $3 \mathrm{~m} / \mathrm{min}$ total measured distance $\quad 50 \mathrm{~mm}$ material

DC06 ZE75/75

- electrolytical galvanized DX54 Z100

hot-dip galvanized

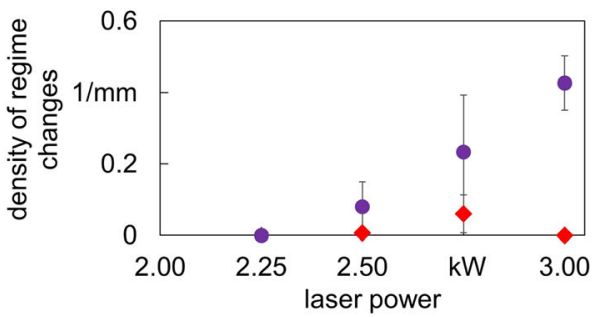


Fig. 6 Recording of the wetting fronts after immediate process stop
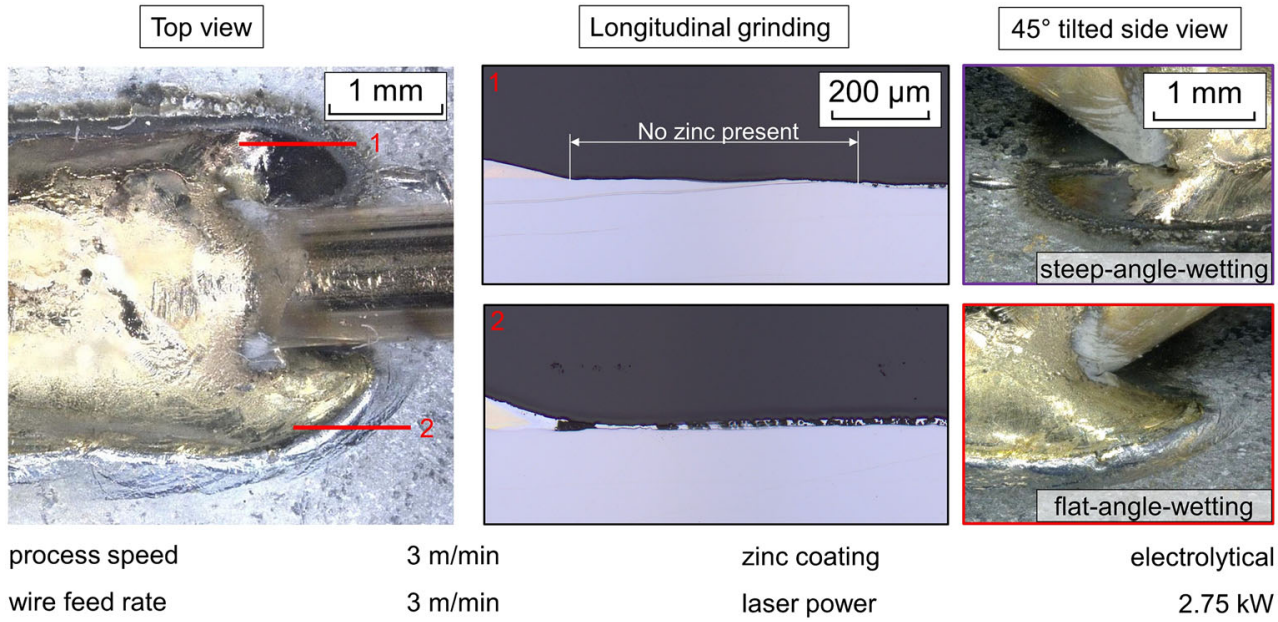

electrolytical

$2.75 \mathrm{~kW}$ not only influences the wetting process in process direction but also transverse to the process direction. Due to an increased wetting in the case of regime transition from steepangle-wetting to flat-angle-wetting by the contact of the wetting front to liquid zinc, the wetting length transverse to the process direction, and by that, the seam width increases (cf. Fig. 4). This local increase of the seam width creates an abrupt transition of the seam width, which is a major defect for the seam edge quality. Therefore, to ensure brazing with high quality seam edges, the transition between the wetting regimes has to be prevented.

The contact of liquid zinc to the wetting fronts in flatangle-wetting results, as shown in Fig. 3, in more wavy seam edges. As described by Reimann, this is led back to a constantly changing wetting length because of changing amounts of zinc concentration in the seam edges even without changing process parameters [11]. In steep-angle-wetting, the variation of the wetting length is lower during the process because the wetting front is not in contact with liquid zinc and a more constant seam width, and by that, a straighter seam edge results. Furthermore, as described before, steep-angle-wetting can occur in both galvanising variants. Therefore, it is concluded that not the type of zinc coating but the prevailing wetting regime is responsible for the resulting seam edge quality.

The wetting regime can be defined within certain limits by the process parameters but is also influenced by process disturbances (cf. Fig. 4). Furthermore, the stability of a wetting regime is, to some extent, self-sustaining. As shown in Fig. 5, for electrolytical galvanised steel and laser power of $2.25 \mathrm{~kW}$, in the lowest suitable laser power for a successful wetting, only steep-angle-wetting occurs. The laser power on this occasion is sufficient to vaporise the zinc layer before wetting. On the other hand, in brazing hot-dip galvanised steel sheets at a laser power of $3.00 \mathrm{~kW}$, in the highest investigated laser power, only flat-angle-wetting occurs because of contact between liquid zinc and the wetting front. But the occurrence of the wetting regime is not only depending on the type of zinc layer. With increasing laser power in electrolytical galvanised steel, also flat-angle-wetting occurs in brazing of electrolytical galvanised steel sheets. This is led back to a lower viscosity of the copper melt for
Fig. 7 Cross sections from both seam edges in one specimen, which differ in wetting regime, for both types of zinc coatings

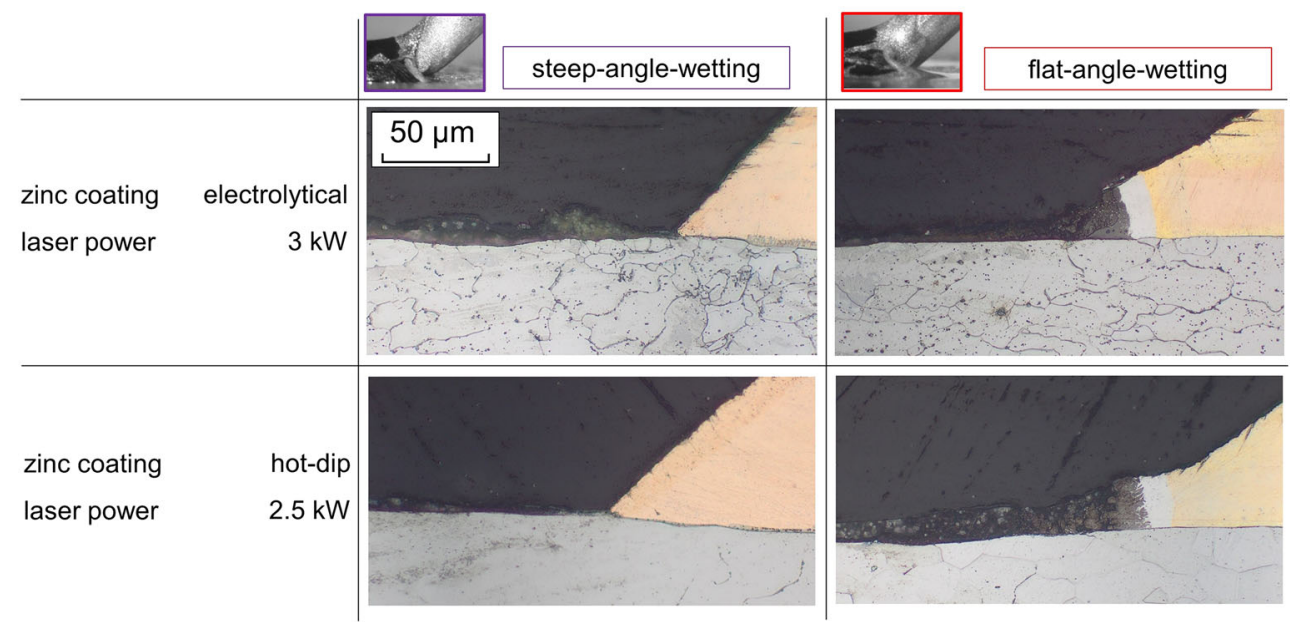


higher temperatures. Process disturbances, like illustrated in Fig. 4, can push the wetting front further forward due to the lower viscosity so that a contact with liquid zinc occurs instead of an evaporation by the laser beam. In this moment, a self-stabilising effect takes place, which prevents the regime from directly turning back to steep-angle-wetting. Parts of the steel sheet, where in the case of steep-angle-wetting a zinc vaporisation occurs, are covered by the wetting front, cf. Fig. 6. The incident radiation at this position heats the copper melt and not the zinc layer of the steel sheet. This shields the surface from radiation and stabilises the regime of flat-angle-wetting. The described shielding effect is a major reason why no permanent zinc evaporation, and by that, no permanent steep-angle-wetting can be achieved for brazing of hot-dip galvanised steel with this setup.

Process disturbances can, for example, melt expulsions due to the vaporisation of zinc through the melt pool. The occurrence is assisted by the evaporation temperature of zinc $\left(907^{\circ} \mathrm{C}\right)$, which is lower than the melting range of the copper filler wire $\left(9651035^{\circ} \mathrm{C}\right)$. Also, spatter ejections in process direction are a possible reason for contacting liquid zinc to the wetting fronts. The target strategy of completely preventing process disturbances in order to prevent regime changes would require very precise process control and process monitoring such as e.g. temperature control. This is considered to be economically not feasible for the industrial production of car bodies. A target strategy that is suitable for electrolytically galvanised sheets is to aim for low laser power. As a result, the melt viscosity remains sufficiently high and a stable connection between the zinc melt and the wetting front cannot be achieved. Hot-dip galvanised steel sheets absorb approximately $20 \%$ less laser radiation (cf. Fig. 2). Therefore, $2.5 \mathrm{~kW}$, the lowest laser power before wetting errors occur, is not sufficient to evaporate the complete zinc layer. Here, on average only $4.32 \%$ of the inspected seam share was brazed with steep-angle-wetting. However, higher laser powers are not suitable because of the mentioned lowering of the viscosity of the copper melt and the higher probability of melting the base materials. A conflict of objectives is present here, which prevents the achieving of steep-angle-wetting by low laser power. This conflict of objectives is assumed to be the main cause of the problems in conventional brazing of hot-dip galvanised steel with high seam edge quality. In order to braze hot-dip galvanised sheets with high seam edge quality, in industrial practice, the zinc layer is evaporated via trifocal intensity distributions prior to the wetting process [16]. This effectively prevents liquid zinc from contacting the wetting front and enables brazing with a permanent steep-angle-wetting regime. Another new approach to prevent regime changes is to change the melt pool dynamics by external mechanical movement. First results showed that a filler wire oscillation superimposed on the wire is capable of this change of melt pool dynamics [20]. Here, further research is planned to influence the wetting behaviour and occurrence of wetting regimes in laser brazing.

\section{Conclusion}

The process monitoring identifies two wetting regimes which mainly influence the seam edge quality and can occur for both types of zinc coatings: flat-angle-wetting and steep-anglewetting.

The following conclusions can be drawn from the investigations:

1. Regime changes during the process lead to an abrupt transition of the seam width and therefore create a major defect for the seam edge quality. Hence, regime transitions have to be prevented for high seam edge quality.

2. The contact of liquid zinc to the wetting fronts has to be avoided by vaporising the zinc prior to the wetting to braze with steep-angle-wetting, which results in higher seam edge quality.

3. The missing process windows for brazing of hot-dip galvanised steel with permanent steep-angle-wetting is led back to a lower absorption of laser radiation compared with the electrolytical galvanised steel and therefore a self-stabilising shielding of the zinc layer from laser radiation by a leading wetting front in the case of flat-anglewetting.

Acknowledgements Furthermore, the authors gratefully acknowledge the collaboration with the members of the project-affiliated committee regarding the support of knowledge, material and equipment over the course of the research. Open access funding provided by projekt DEAL.

The "BIAS ID" nos. are part of the figures and allow the retrace ability of the results with respect to mandatory documentation required by the funding organisation.

Funding information The IGF-Project no.: 19.987 N/DVS-No.: 06.3047 of the "Forschungsvereinigung Schweißen und verwandte Verfahren e.V." of the German Welding Society (DVS), Aachener Str. 172, 40223 Düsseldorf was funded by the Federal Ministry for Economic Affairs and Energy (BMWi) via the German Federation of Industrial Research Associations (AiF) in accordance with the policy to support the Industrial Collective Research (IGF) on the orders of the German Bundestag.

Open Access This article is licensed under a Creative Commons Attribution 4.0 International License, which permits use, sharing, adaptation, distribution and reproduction in any medium or format, as long as you give appropriate credit to the original author(s) and the source, provide a link to the Creative Commons licence, and indicate if changes were made. The images or other third party material in this article are included in the article's Creative Commons licence, unless indicated otherwise in a credit line to the material. If material is not included in the article's Creative Commons licence and your intended use is not permitted by statutory regulation or exceeds the permitted use, you will need to obtain permission directly from the copyright holder. To view a copy of this licence, visit http://creativecommons.org/licenses/by/4.0/. 


\section{References}

1. Haldenwanger H-D, Schmid G, Korte M et al (1999) Laserstrahlhartlöten für Karosseriesichtteile in Claas-AOberflächenqualität. Schweißen und Schneiden 99. DVS reports 204:191-196

2. Schubert H, Hauser S (2004) Laserstrahlhartlöten mit Festkörperlaser - Status und Ausblick. Hart- und Hochtemperaturlöten und Diffusionsschweißen, DVS reports 231:205-206

3. Graudenz M, Heitmanek M (2012) Laser tools in the manufacturing process. LTJ 9(4):24-27. https://doi.org/10.1002/latj.201290049

4. Hornig H (2006) Praxis des Laserstrahlhartlötens im Fahrzeugbau. Proceedings of 5 th Laser-Anwenderforum

5. Husner J, Luft A, Olaineck C (2003) Laserlöten im Automobilbau. ThyssenKrupp techforum

6. Milberg J, Trautmann A (2009) Defect-free joining of zinc-coated steels by bifocal hybrid laser welding. Prod Eng Res Devel 3(1):9 15. https://doi.org/10.1007/s11740-008-0140-2

7. Gatzen M, Radel T, Thomy C et al (2014) The role of zinc layer during wetting of aluminium on zinc-coated steel in laser brazing and welding. Phys Procedia 56:730-739. https://doi.org/10.1016/j. phpro.2014.08.080

8. Reimann W, Pfriem S, Hammer T et al (2017) Influence of different zinc coatings on laser brazing of galvanized steel. J Mater Process Technol 239:75-82. https://doi.org/10.1016/j.jmatprotec.2016.08. 004

9. Reimann W (2016) Trifocal laser brazing of hot-dip galvanized steel. EALA - European Automotive Laser Applications : 16-17 February 2016, Bad Nauheim, Germany: conference proceedings

10. Gürtler Y (2016) Laserlöten feuerverzinkter Bleche. LaserCommunity

11. Reimann W (2018) Entwicklung eines Laserstrahl-Lötverfahrens für schmelztauchveredelte Karosseriebauteile. Dissertation. In: Dilger K (ed) Forschungsberichte des Instituts für Füge- und Schweißtechnik, vol 47. Shaker Verlag, Aachen

12. Schmidt M, Otto A, Kägeler C (2008) Analysis of YAG laser lapwelding of zinc coated steel sheets. CIRP Ann 57(1):213-216. https://doi.org/10.1016/j.cirp.2008.03.043
13. Koltsov A, Bailly N, Cretteur L (2010) Wetting and laser brazing of $\mathrm{Zn}$-coated steel products by $\mathrm{Cu}-\mathrm{Si}$ filler metal. J Mater Sci 45(8): 2118-2125. https://doi.org/10.1007/s10853-009-3949-y

14. Gatzen M, Radel T, Thomy C et al (2014) Wetting behavior of eutectic Al-Si droplets on zinc coated steel substrates. J Mater Process Technol 214(1):123-131. https://doi.org/10.1016/j. jmatprotec.2013.08.005

15. Reimann W, Dobler M, Goede M, Schmidt M, Dilger K (2017) Three-beam laser brazing of zinc-coated steel. Int J Adv Manuf Technol 90(1-4):317-328. https://doi.org/10.1007/s00170-0169361-2

16. Luft A, Baumann M (2016) Laser brazing of hot dip galvanized sheets with homogenizing module and tailored spot geometry. Proceedings of 17. European Automotive Laser Applications EALA 2016

17. Grimm A, Schmidt M (2009) Possibilities for online process monitoring at laser brazing based on two dimensional detector systems. Proceedings of 28th International Congress on Applications of Laser \& Electro-Optics (ICALEO): 537-544

18. Heuberger E, Schmid D, Weberpals J-P et al. (2018) Influence of the brazing speed on the seam characteristics in laser beam brazing of zinc coated steel. Proceedings of the International Congress on Applications of Lasers and Electro-Optics ICALEO, Orlando, USA, Paper \#903, Hrsg.: C. Leyens

19. Kügler H, Vollertsen F (2018) Determining absorptivity variations of multiple laser beam treatments of stainless steel sheets. JMMP 2(4). https://doi.org/10.3390/jmmp2040084

20. Mattulat T, Kügler H, Vollertsen F (2019) Influence of filler wire oscillation on the seam texture in laser beam brazing. Production at the leading edge of technology - Proceedings of the 9th Congress of the German Academic Association for Production Technology (WGP), Eds.: Wulfsberg, J.P.; Hintze, W.; Behrens, B.-A., Hamburg: 359-368

Publisher's note Springer Nature remains neutral with regard to jurisdictional claims in published maps and institutional affiliations. 